\title{
Erratum to: Size, Site Fidelity, and Overlap of Home Ranges and Core Areas in the Socially Monogamous Owl Monkey (Aotus azarae) of Northern Argentina
}

\section{Flurina M. Wartmann • Cecilia P. Juárez • Eduardo Fernandez-Duque}

\section{Erratum to: Int J Primatol DOI 10.1007/s10764-014-9771-7}

The original version of this article unfortunately contained a mistake. The legends of Figs. 3 and 4 have been reversed.

The correct figure legends are as follows:

Fig 3. Owl monkey mean annual ranges for the six focal groups in Estancia Guaycolec ranch in Formosa Province, Argentina, 1998-2008.

Fig 4. Owl monkey group annual ranges, core areas, and overlaps for the six focal groups in Estancia Guaycolec ranch in Formosa Province, Argentina. Data for 2004 are displayed as an example.

The authors apologize for this mistake.

The online version of the original article can be found at http://dx.doi.org/10.1007/s10764-014-9771-7.

F. M. Wartmann $(\bowtie)$

Department of Geography, University of Zurich, Winterthurerstrasse 190, CH-8057 Zurich, Switzerland e-mail: flurina.wartmann@geo.uzh.ch

C. P. Juárez • E. Fernandez-Duque

CECOAL-Conicet, C. P. 3400 Corrientes, Argentina

E. Fernandez-Duque

Department of Anthropology, University of Pennsylvania, Philadelphia, PA 19104, USA 